\title{
The MONitoring Dialysis Outcomes (MONDO) Initiative
}

\author{
Len A. Usvyat ${ }^{a}$ Yosef S. Haviv ${ }^{b}$ Michael Etter ${ }^{c}$ Jeroen Kooman ${ }^{d}$ \\ Daniele Marcelli ${ }^{\mathrm{e}}$ Cristina Marelli ${ }^{\mathrm{f}}$ Albert Power $^{\mathrm{g}}$ Ted Toffelmire $^{\mathrm{h}}$ \\ Yuedong Wangi Peter Kotanko ${ }^{\mathrm{a}}$
}

${ }^{a}$ Renal Research Institute, New York, N.Y., USA; ${ }^{b}$ Hadassah-Hebrew University Medical Center, Jerusalem, Israel;

${ }^{c}$ Fresenius Medical Care Asia Pacific, Hong Kong, SAR, China; dUniversity Hospital Maastricht, Maastricht,

The Netherlands; ${ }^{\mathrm{e}}$ Fresenius Medical Care, Bad Homburg, Germany; ${ }^{\mathrm{f}}$ Fresenius Medical Care Latin America, Buenos Aires, Argentina; IImperial College Renal \& Transplant Centre, London, UK; ${ }^{\text {h}}$ Queen's University, Kingston, Ont., and Fresenius Medical Care Canada, Richmond Hill, Ont., Canada; 'University of California at Santa Barbara, Santa Barbara, Calif., USA

\section{Key Words}

Electronic medical records - Global dialysis database • Global hemodialysis patient data $\cdot$ Health information systems - Longitudinal analyses - MONDO initiative • MONitoring Dialysis Outcomes initiative

\section{Abstract}

Background: Systematic collection and analysis of global hemodialysis patient data may help to improve patient outcomes. Methods: The MONitoring Dialysis Outcomes (MONDO) initiative comprises data from eight dialysis providers worldwide. Data are combined into one repository. Extensive procedures are employed to merge data across countries and providers. Results: The MONDO database comprises longitudinal data of currently 128,000 hemodialysis patients from 26 countries on five continents. Here we report data from 62,345 incident hemodialysis patients. We found lower catheter rates in South-East Asia and Australia, lower hemoglobin levels in South-East Asia, and a higher prevalence of diabetes in North America. Longitudinal analyses suggest that there is a decline in interdialytic weight gain and serum phosphorus and an increasing neutrophilto-lymphocyte ratio before death in all regions studied.
Conclusions: While organizationally lean and low-cost, MONDO is the largest global dialysis database initiative to date, with a particular focus on high longitudinal data density and geographical diversity.

Copyright @ 2013 S. Karger AG, Basel

\section{Background}

Data and data-driven decision support systems in healthcare can improve patient outcomes [1]. In the USA, doctors and hospitals are required to move to computerized medical records by 2015 [2]. With electronic medical records (EMR) and health information systems becoming more widely available, not only in the USA, more international databases are likely to sprout [3]. However, global health databases are currently scarce. While needed to address broad research questions, worldwide registries of not just cross-sectional snapshots but longitudinal data-rich patient-specific databases are lacking. The World Health Organization (WHO) comes closest to having some global health status information registries, yet the WHO data is mostly limited to cross-sectional descriptive information. Many countries have domestic

\section{KARGER}

Fax +4161306 1234

E-Mail karger@karger.ch

www.karger.com (c) $2013 \mathrm{~S}$. Karger AG, Basel

0253-5068/13/0353-0037\$38.00/0

Accessible online at:

www.karger.com/bpu
Len A. Usvyat

Renal Research Institute

207 East 94thStreet, Suite 303

New York, NY 10128 (USA)

E-Maillusvyat@ rriny.com 
registries of patient information that are discipline-specific, particularly for chronic diseases. For example, in Australia, the National Joint Replacement Registry collects data on patients with joint replacement. In England, the United Kingdom Association of Cancer Registries collects oncology data, and in the USA, the Cardiac Arrest Registry is collected by Centers for Disease Control. Some limited-purpose databases are created for specific studies. For example, INTER-HEART was created as a global case-control study that seeks to understand the importance of both traditional and emerging risk factors for acute myocardial infarction. The findings will be relevant for developing health policies that can be applied to different countries and ethnic groups [4].

Similar to other fields of medicine, dialysis data are generally kept in country-specific registries, such as the United States Renal Data System (USRDS). Most renal registries rely on voluntary reporting and collect limited information about practice patterns [5]. Yet, even these databases are not linked on a global basis. In fact, global databases of dialysis patients are very limited with the notable exception of Dialysis Outcomes and Practice Patterns Study (DOPPS). DOPPS is a prospective cohort study of hemodialysis (HD), and more recently peritoneal dialysis, practices based on the collection of longitudinal data for a random sample of patients and dialysis units in currently 12 countries (Australia, Belgium, Canada, France, Germany, Japan, Italy, New Zealand, Spain, Sweden, the UK, and the USA). Since 1996, data collection has yielded detailed information on more than 55,000 patients in over 600 dialysis facilities [6]. In fact, DOPPS proved to be one of the success stories in dialysis research, providing insights into practice patterns and their relationship to outcomes. However, DOPPS collects longitudinal data only up to four times a year and usually patients are not followed over many years. In contrast, electronic health records of large dialysis providers frequently contain per-treatment data and most patients are followed throughout the whole time on dialysis [7]. ERA-EDTA has an international renal replacement registry that collects and merges data from the various registries in Europe. These data include the patient's date of birth, gender, cause of renal failure, date of start of first renal replacement therapy, history of renal replacement therapy with dates and changes of modality, treatment center, date and cause of death and information concerning transfer from or to other renal registries [8]. Ways of reporting is different in various countries and Nephro-QUEST initiative was started to standardize data collection across European countries [9]. Other than DOPPS, no global dialysis database exists, although patients, healthcare providers, and organizations with a global outreach (e.g. KDIGO, Kidney Disease: Improving Global Outcomes) may benefit from research possible through global CKD registries [10]. An ideal global dialysis database should contain a wealth of longitudinal clinical data as well as static patient information, such as patient demographics. Data should be agglomerated in such a way that they can be analyzed transparently from one country to another.

The inception of the MONitoring Dialysis Outcomes (MONDO) initiative was stimulated by research from the Renal Research Institute (RRI), New York, which suggested that in chronic HD patients treated in facilities of the RRI and Fresenius Medical Care North America (FMCNA) longitudinal trends in systolic blood pressure $[11,12]$, body weight and serum albumin levels [13] were associated with an increased mortality risk. Later it was shown that changes in body temperature were also associated with poorer outcomes [14]. Noteworthy, these dynamic changes were obvious already months before death. These observations in US dialysis populations lead to an obvious question: are these observations specific for US facilities or do patients in other countries demonstrate comparable longitudinal patterns? Noteworthy, HD mortality rates differ substantially between countries and facilities $[15,16]$. In order to further explore whether or not these patterns before death exist elsewhere, we needed access to longitudinal HD patient data from around the world. This need led to the foundation of the MONDO initiative, where a diverse group of dialysis providers agreed to facilitate analysis of individual EMR. We named the consortium MONDO to demonstrate the global nature of our initiative as well as the importance of leveraging the use of worldwide data to improving dialysis patient outcomes. Data managers and analysts from all MONDO members are involved in data extraction and analysis. Statistical data analysis is conducted under the oversight of a committee encompassing statisticians and epidemiologists from the MONDO members. While it was a daunting challenge to combine data across a host of databases, MONDO members now have access to data of nearly 130,000 HD patients and close to 23 million HD treatments between 2000 and 2012. A distinctive characteristic of MONDO is that we are gathering data at a patient and (in most instances) treatment level. This feature allows us to analyze individual patients longitudinally. Specifically, we are collecting data on patient demographics, comorbidities, HD treatment parameters, laboratory, and adequacy parameters. We are also collecting all morbidity and mortality outcomes. 
In this report we describe the MONDO initiative, the approach taken to conduct studies, delineate incident patient characteristics as well as provide sample longitudinal patterns after initiation of HD and death.

\section{Methods}

\section{Regulatory}

Regulatory aspects can be divided into those associated with patient-specific confidentiality issues, which are usually subject to national law and compliance regulations specific to dialysis provider. All data are de-identified and do not contain protected health information such as dates of birth, patient names or addresses. Since the data comes directly from the provider-specific EMR systems, all confidential patient information is removed at that time. In addition to all aspects of patient confidentiality, MONDO is cognizant of the provider-specific compliance regulations. For example, while most data from MONDO members are analyzed at RRI and the Department of Statistics and Applied Probability, University of California at Santa Barbara, our consortium welcomes members who prefer to analyze their data locally.

\section{Funding}

MONDO has a lean organizational structure and does not have a joint budget to cover expenses and overhead. Expenses are primarily related to data analysis and statistical support. Data collection, quality control, storage, and extraction are in the responsibility of each MONDO member. Unless prevented by providerspecific compliance regulations, data analysis is done at the RRI and the University of California, Santa Barbara; most of the related expenses are covered by RRI. MONDO members hold in person meetings minimally twice a year in conjunction with international conferences such as ASN, ERA-EDTA or WCN. The travel costs are borne by each individual MONDO member.

\section{Database Specifics}

MONDO contains HD patient data from eight dialysis providers worldwide with 1,052 dialysis clinics on five continents; data from Africa is forthcoming. The current MONDO members are Maastricht University Hospital (Maastricht), Hadassah Medical Center (Hadassah), Imperial College Renal and Transplant Center (Imperial College), Kingston General Hospital/Queen's University (Queen's), Fresenius Asia Pacific (FMC Asia Pacific), Fresenius Medical Care Europe, Middle East, and Africa (FMC Europe), Fresenius Medical Care Latin America (Latin America), and RRI (table 1). Each provider has an EMR system that tracks patient data and is used in the clinics. We combined the information from these EMR systems into one database. The data we collected thus far are retrospective, but we plan to update it at least every 2 years. We are currently collecting data on in-center HD patients. Since some MONDO member organizations provide peritoneal dialysis, we plan to extend our activities to this area. Most data we collect are from January 1,2000 onwards or the date when the HD clinic data became available. Since the MONDO members provide care to only a subset of the HD patients in each respective country, the percentage of represented current prevalent patients varies: it is as low as about $1 \%$ in the USA, and over $40 \%$ in Portugal and Argentina. Except in countries contributing only one to two facilities, the majority of clinics are representatively spread over the country. For example, in the USA, RRI clinics are located in California, Michigan, Illinois, North Carolina, New York, and Connecticut.

Depending on the database, data elements are either entered manually in the HD clinics or automatically transferred from another source. Manually entered data are subject to rigorous internal quality control mechanisms pursuant to country-specific database regulations. In most European clinics, Maastricht, Hadassah Medical Center and all of the RRI clinics, laboratory results are directly imported electronically from the clinical laboratories. More recently, treatment parameters from FMC Europe are also automatically entered. Irrespective of entry modality, all data undergo a comparable cleaning process, where records with implausible/impossible entries are set to a null value. In some cases, patients with improbable key dates are removed.

Table 2 lists the data domains by MONDO member organization. Since we use existing EMR systems to collect patient data and do not require additional data entry forms, we are reliant on what is captured in each database. Hence, the information presented in table 2 is to be used as a reference on what types of data are available. We collect both clinic- and patient-specific information. Patient-specific information includes: admission and discharge data, background patient information, comorbidities, vital signs recorded before, after, and during $\mathrm{HD}$, dialysis prescription, in-center administered medications, laboratory data, residual renal function, vascular access, home medications, and in-center or outpatient procedures. With the exceptions of FMC Asia Pacific, FMC Latin America and Hadassah Medical Center, treatment data are gathered for each HD session. In most databases all laboratory results are reported whenever they become available, which may be on multiple occasions in the course of a month. In contrast, FMC Asia Pacific and FMC Latin America provide laboratory data once a month. Because units of laboratory measurement may differ between countries, we convert them into consistent units (usually SI units). Differences in laboratory methods are harder to account for. Serum albumin concentration is measured by the bromocresol green method in most databases. The bromocresol purple method was used in Portugal and some HD clinics in Asia. To ensure comparability between the two methods, bromocresol purple measurements were transformed to bromocresol green values [17].

An important consideration is how to deal with the fact that some databases, by design, capture more variables than others. This is a vital decision because most analyses involve variables that exist across all databases - in essence, the 'largest common number of variables'. Basically, we include variables with the highest research priority. However, we have the option of adding more variables in the future from the provider-specific EMR system. For example, FMC Europe collects a host of laboratory measures that are less commonly used in the USA. Most issues in combining the data arise from the country-specific practices and regulations. Medical practices vary significantly across countries and providers, ranging from small issues such as frequency of blood pressure measurement, to specifics of drug therapy. Reimbursement systems and overarching quality goals are specific for each provider and country. In countries where patients cannot afford certain medications, e.g. cardioprotective drugs or iron supplements, reasons for lack of medication are different compared to the USA. Similarly, some countries allow therapies (e.g. hemo- 
Table 1. Providers, number of patients and dialysis treatments in the current MONDO dataset

\begin{tabular}{|c|c|c|c|c|c|c|}
\hline $\begin{array}{l}\text { Provider of dialysis } \\
\text { (abbreviated name) }\end{array}$ & $\begin{array}{l}\text { Countries/regions } \\
\text { (existing database) }\end{array}$ & $\begin{array}{l}\text { Date range } \\
\text { (existing database) }\end{array}$ & $\begin{array}{l}\text { Number } \\
\text { of clinics } \\
\text { (approximate) }\end{array}$ & $\begin{array}{l}\text { Total } \\
\text { HD patients } \\
\text { (existing database) }\end{array}$ & $\begin{array}{l}\text { Total } \\
\text { HD treatments } \\
\text { (existing database) }\end{array}$ & $\begin{array}{l}\text { National HD } \\
\text { representation } \\
\text { (approximate) }\end{array}$ \\
\hline $\begin{array}{l}\text { Renal Research Institute } \\
\text { (RRI) }\end{array}$ & USA & $1 / 2000-12 / 2010$ & 50 & 34,636 & $9,391,482$ & $1 \%$ \\
\hline $\begin{array}{l}\text { Maastricht University } \\
\text { Hospital (Maastricht) }\end{array}$ & The Netherlands & $1 / 2000-6 / 2012$ & 2 & 1,978 & 159,000 & $3 \%$ \\
\hline $\begin{array}{l}\text { Hadassah Medical Center } \\
\text { (Hadassah) }\end{array}$ & Israel & $1 / 2006-12 / 2011$ & 1 regional center & 219 & 8,000 & $4 \%$ \\
\hline $\begin{array}{l}\text { Fresenius Asia Pacific } \\
\text { (FMC Asia Pacific) }\end{array}$ & $\begin{array}{l}\text { Australia } \\
\text { China (Hong Kong) } \\
\text { China (Taiwan) } \\
\text { Singapore } \\
\text { South Korea }\end{array}$ & $1 / 2003-12 / 2010$ & 200 & $\begin{array}{r}903 \\
153 \\
5,238 \\
459 \\
1,318 \\
\end{array}$ & $\begin{array}{r}12,991 \\
2,046 \\
150,085 \\
7,514 \\
20,174 \\
\end{array}$ & $\begin{array}{l}1-20 \% \text { depending } \\
\text { on the country }\end{array}$ \\
\hline $\begin{array}{l}\text { Fresenius Medical Care } \\
\text { Europe, Middle East, and } \\
\text { Africa (FMC Europe) }\end{array}$ & $\begin{array}{l}\text { Bosnia } \\
\text { Czech Republic } \\
\text { France } \\
\text { Hungary } \\
\text { Ireland } \\
\text { Italy } \\
\text { Poland } \\
\text { Portugal } \\
\text { Romania } \\
\text { Russia } \\
\text { Serbia } \\
\text { Slovakia } \\
\text { Slovenia } \\
\text { Spain } \\
\text { Sweden } \\
\text { Turkey } \\
\text { UK }\end{array}$ & $1 / 2000-12 / 2010$ & 600 & $\begin{array}{r}268 \\
1,944 \\
1,811 \\
4,201 \\
259 \\
3,934 \\
4,081 \\
11,794 \\
3,017 \\
893 \\
428 \\
886 \\
557 \\
12,813 \\
48 \\
11,759 \\
7,407 \\
\end{array}$ & $\begin{array}{r}21,832 \\
716,930 \\
180,195 \\
823,848 \\
38,664 \\
1,124,860 \\
320,301 \\
2,637,298 \\
618,170 \\
151,520 \\
70,482 \\
59,848 \\
144,142 \\
2,226,273 \\
7,744 \\
1,887,850 \\
1,181,620 \\
\end{array}$ & $\begin{array}{l}3-48 \% \text { depending } \\
\text { on the country }\end{array}$ \\
\hline $\begin{array}{l}\text { Fresenius Medical Care } \\
\text { Latin America } \\
\text { (Latin America) }\end{array}$ & Argentina & $1 / 2000-12 / 2010$ & 200 & 17,758 & 563,830 & $40 \%$ \\
\hline Total & 26 & & 1,052 & 128,762 & $22,526,699$ & \\
\hline
\end{tabular}

diafiltration) which may not be available in others. Many of these differences present their own layer of complexity, while others create new research opportunities. Causes of ESRD, death or hospitalization, and comorbid conditions are collected differently across databases. While some use ICD-9 or ICD-10 codes, others have developed specific descriptors. While we collect data in the original method used by each provider, we created a process that merges these schemas and allow for unified reporting and analytics. This method merges the data in such a way that has events recorded on a per-day basis, such as treatments, hospitalization records, laboratory results and others.

\section{Statistical Methods}

In addition to measurements at dialysis initiation, the MONDO database contains a wealth of longitudinal measurements. As indicated previously, our initial aim was to investigate the existence of characteristic dynamics before death or after the start of dialysis. To that end we employ a specific analytical methodology. Here we report as examples the dynamics of interdialytic weight gain (IDWG), neutrophil-to-lymphocyte ratio (NLR) and serum phosphorus. We refer to the longitudinal process after the initiation of dialysis as a 'forward process' since we follow the process forward in time; in contrast, we refer to the longitudinal process before death as a 'backward process' since we trace the process backward in time. Understanding these dynamics is important in comprehending a more complete picture of what happens to dialysis patients over time as well as coming up with a predictive model that alerts clinicians to patients who are at increased risk of hospitalization or death. We need to estimate the mean functions of the forward and backward processes for certain populations of patients based on noisy measurements. Some of the variables are measured weekly, some are measured monthly, and some are measured at irregular times. For simplicity, we assume in the following discussion that monthly measurements are available (missing months are allowed).

We first describe the statistical methods for estimating the mean functions of the forward processes. We denote $\mathrm{Y}(\mathrm{t})$ as the forward process of a variable of interest $t$ months after the start of dialysis from a patient in a specific population, and $\mathrm{T}$ as the survival time of this patient after the start of dialysis. We define the 


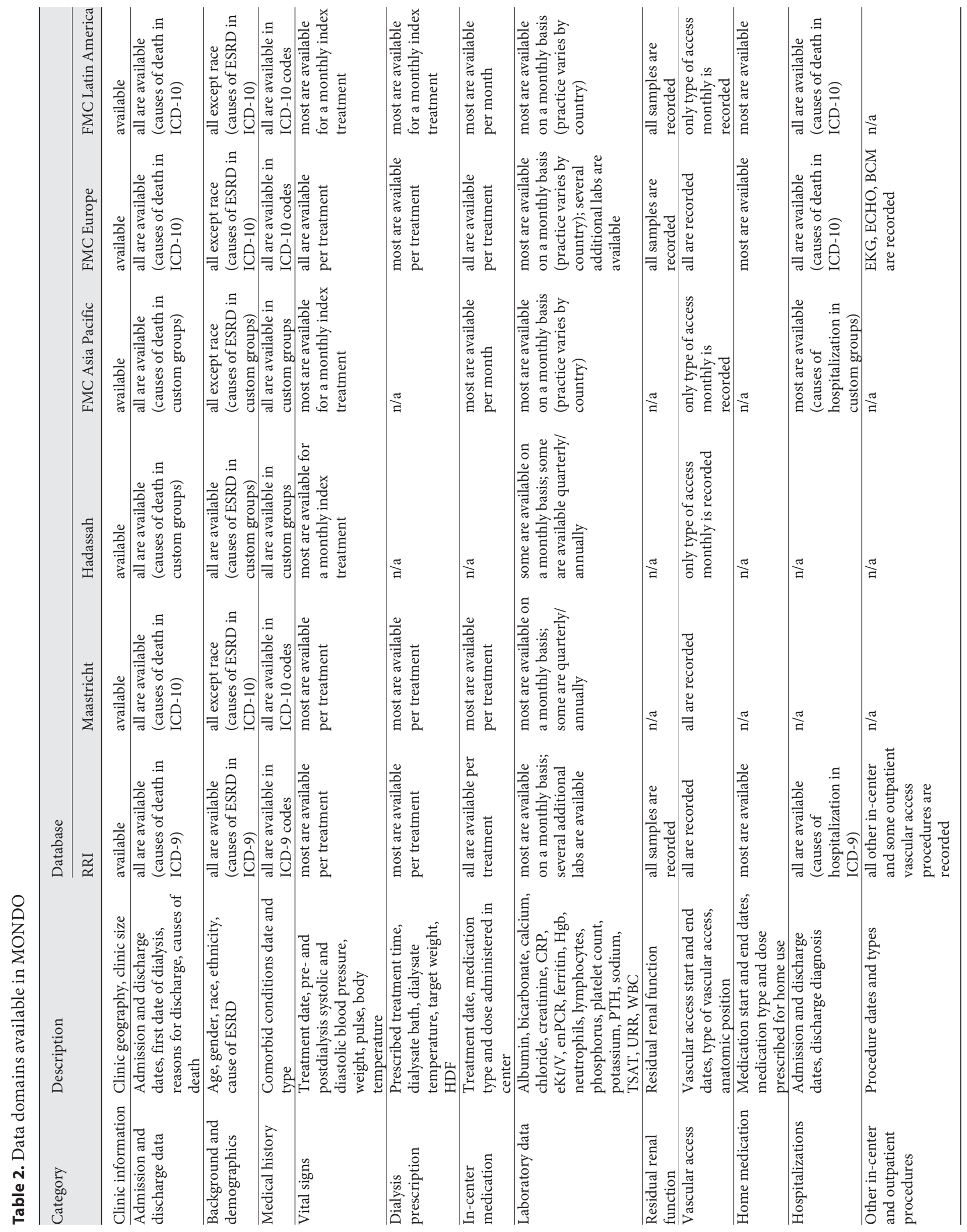


partial conditional mean at month $\mathrm{t}$ as $\mathrm{E}(\mathrm{Y}(\mathrm{t}) \mid \mathrm{T}>\mathrm{t})$ which represents the expectation of the forward process at month $t$ conditional on this patient survived longer than $t$ months (i.e. the patient is alive at month $\mathrm{t}$ ) [18]. To estimate $\mathrm{E}(\mathrm{Y}(\mathrm{t}) \mid \mathrm{T}>\mathrm{t})$, we compute average measurements of the variable of interest at month $t$ among all patients who are still alive at month $\mathrm{t}$. These monthly averages usually have relatively large variations. To estimate the forward pattern and its trajectory, we treat these average measurements as observations and fit a quintic spline model. A quintic spline is a piecewise quintic function with a knot at each month and the fourth derivative of the function is continuous [19]. We use the quintic spline instead of the popular cubic spline such that the estimated trajectory is smooth. We also estimate the trajectory of the first derivative of the quintic spline function, which can be interpreted as 'velocity'. A similar method is used to investigate processes traced backward in time. We denote $\mathrm{Y}(\mathrm{t})$ as the backward process of a variable of interest $t$ months before death, and $\mathrm{T}$ as the survival time of this patient after the start of dialysis. We define the partial conditional mean $t$ months before death as $\mathrm{E}(\mathrm{Y}(\mathrm{t}) \mid \mathrm{T}>\mathrm{t})$ which represents the expectation of the backward process $t$ months before death conditional on this patient survived longer than $t$ months. The condition $\mathrm{T}>\mathrm{t}$ avoids measurements before the start of dialysis. To estimate $\mathrm{E}(\mathrm{Y}(\mathrm{t}) \mid \mathrm{T}>\mathrm{t})$, we compute average measurements of the variable of interest $t$ months before death among all patients who survived longer than $\mathrm{t}$ months. Then we fit a quintic spline model to these averages to get estimates of the mean function and its trajectory. We use the SSR function in the ASSIST R package to fit a quintic spline [20]. We select the smoothing parameter using the generalized maximum likelihood method and construct confidence intervals (CIs) for the mean functions and their trajectories using the bootstrap method [19].

To provide an overview of some characteristics of incident HD patients, we used data from 62,345 incident patients from 25 countries. Incident patients were classified as those whose in-center treatment was within 90 days of their first date of dialysis. Countries are stratified by the geographical subregions as classified by the United Nations [21] as North America (USA), South America (Argentina), South-East Asia (Singapore), Eastern Asia (Hong Kong, Korea, and Taiwan), Western Asia (Israel and Turkey), Eastern Europe (Czech Republic, Hungary, Poland, Romania, Russia, and Slovakia), Southern Europe (Italy, Portugal, Serbia, Slovenia, Spain and Bosnia), Western Europe (France), Northern Europe (Sweden, Ireland, and UK), and Australia.

\section{Results}

The MONDO consortium encompasses dialysis providers from 26 countries and approximately 1,052 dialysis clinics. The precise number of clinics varies over time since dialysis providers may add or close facilities. Longitudinal data are available from over 128,000 patients and close to 22.6 million HD treatments (table 1).

For this analysis, we studied 62,345 incident HD patients: 11,078 patients from North America, 14,341 from South America, 903 from Australia, 6,709 from Eastern
Asia, 459 from South-East Asia, 4,240 from Western Asia, 2,957 from Northern Europe, 6,662 from Eastern Europe, 14,551 from Southern Europe, and 445 from Western Europe. Mean age (in years; sorted from low to high (95\% CI)) is in South-East Asia: 56 (54.6-57.3), Eastern Asia: 58.9 (58.5-59.2), South America: 59.8 (59.660.1), Western Asia: 60.2 (59.8-60.7), Western Europe: 62.1 (60.5-63.8), North America: 62.3 (62-62.6), Eastern Europe: 63 (62.7-63.4), Northern Europe: 63.8 (63.164.4), Southern Europe: 65.5 (65.2-65.7), and Australia: 65.9 (64.9-67). The percentage of male patients is in Eastern Asia: 53\%, Eastern Europe: 55\%, South-East Asia: 56\%, North America: 57\%, South America: 57\%, Western Asia: 57\%, Southern Europe: 61\%, Northern Europe: 63\%, Western Europe: 64\%, and Australia: 66\%.

Figure 1 presents selected comorbid conditions and access types at the initiation of dialysis. Figure 2 depicts laboratory characteristics at dialysis initiation. In addition to descriptive characteristics of incident patients, we also present examples of forward and backward analyses. Figure 3 shows forward dynamics of IDWG, NLR, and phosphorus levels in incident HD patients by continent (North America, South America, Europe, Asia, and Australia). Figure 4 depicts backward dynamics of IDWG, NLR, and phosphorus levels prior to death.

\section{Discussion}

In the current analysis, we present the characteristics of incident HD patients in the MONDO database. Studies have shown that certain patient characteristics such as older age, catheter vascular access, albumin $<3.5 \mathrm{~g} / \mathrm{dl}$, phosphorus $<3.5 \mathrm{mg} / \mathrm{dl}$, cancer, and congestive heart failure are associated with poor outcomes [22]. Here we aim to describe differences between patients and their disease status as they enter dialysis treatment. While no other studies contain data on all the geographic regions in question, DOPPS findings have shown that European and American patients tend to be older than the patients in Japan [5]. Similar to DOPPS findings, more than half of our patients are male [5]. The percentage of diabetic patients is highest in North America, again consistent with DOPPS. Our data suggests that patients in Eastern Asia have the lowest percentage of patients with catheters while patients in North and South America have the highest percentage of patients with catheters at the initiation of dialysis. The Australian findings are consistent with the ANZDATA [23]. Systolic blood pressures appear lowest in South America and Western Asia, yet are quite 


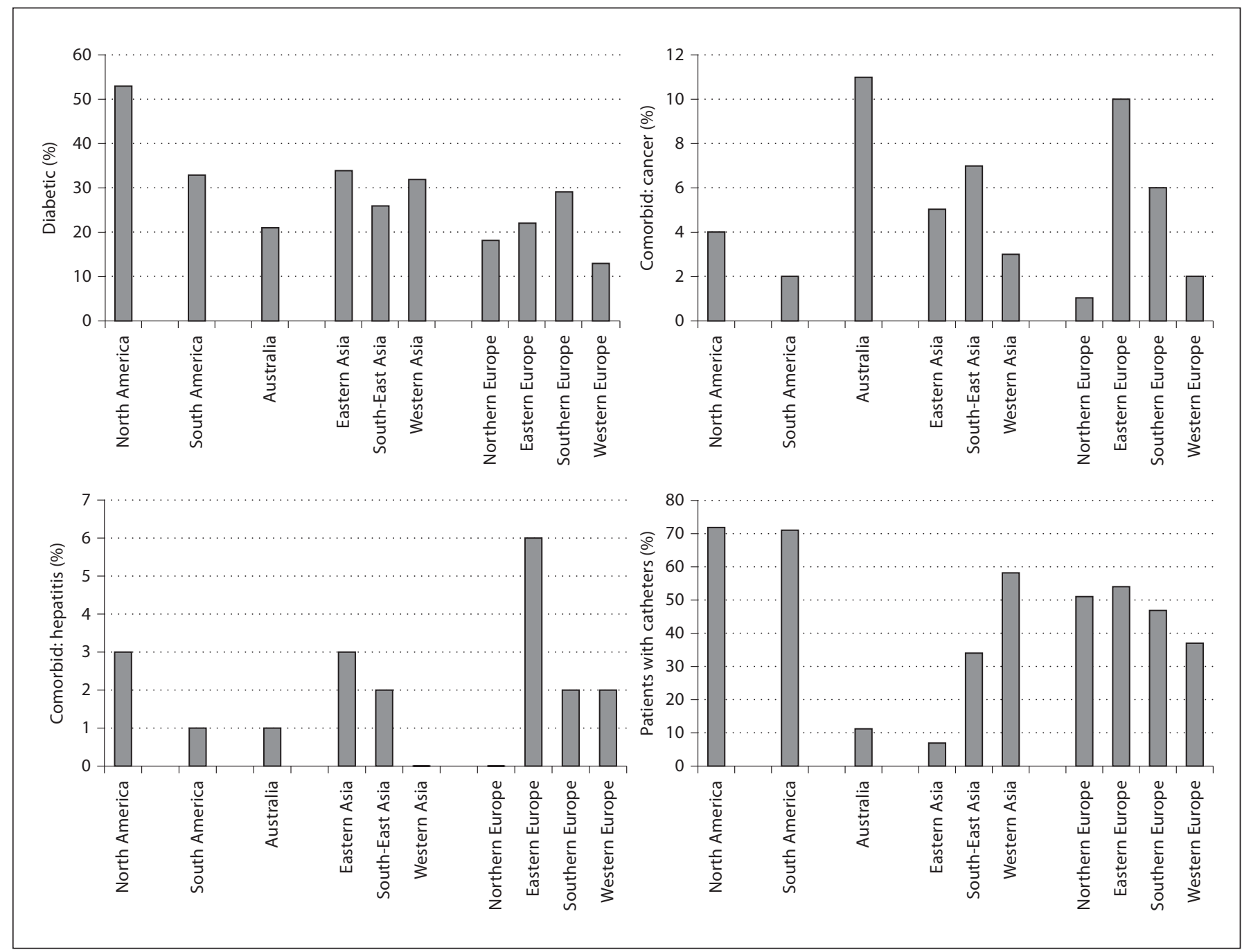

Fig. 1. Comorbid conditions and access type at the start of dialysis by geographic region.

similar across other regions of the world ranging between 135 and $150 \mathrm{~mm} \mathrm{Hg}$. Reasons for these differences are unknown but could be related to patient comorbidities or drug therapy. Hemoglobin levels appear notably lower in South-East Asia which may be due to lower ESA use in that region. Patients start with varying levels of albumin ranging from $3.4 \mathrm{~g} / \mathrm{dl}$ in Northern Europe to $3.85 \mathrm{~g} / \mathrm{dl}$ in Australia. Patients in East Asia and Southern Europe have the next highest levels of albumin which may explain their better survival rates. Serum creatinine levels appear highest in East and South-East Asia. Access type, comorbidities, laboratory and clinical parameters at the initiation of dialysis are different across the world and may be associated with differences in survival, while longitudinal patterns after the start of dialysis or before death appear similar.

Prior RRI research suggested that in chronic HD patients treated in the USA, a decline in systolic blood pressure [11, 12], body weight and serum albumin levels [13] was associated with an increased mortality risk. Current analysis of the MONDO data of IDWG, serum phosphorus and NLR shows that significant changes in these parameters occur before death: IDWG and serum phosphorus decline, while NLR increases. The similarities in these patterns are apparent irrespective of the initial levels. Declines in IDWG and serum phosphorus may sug- 

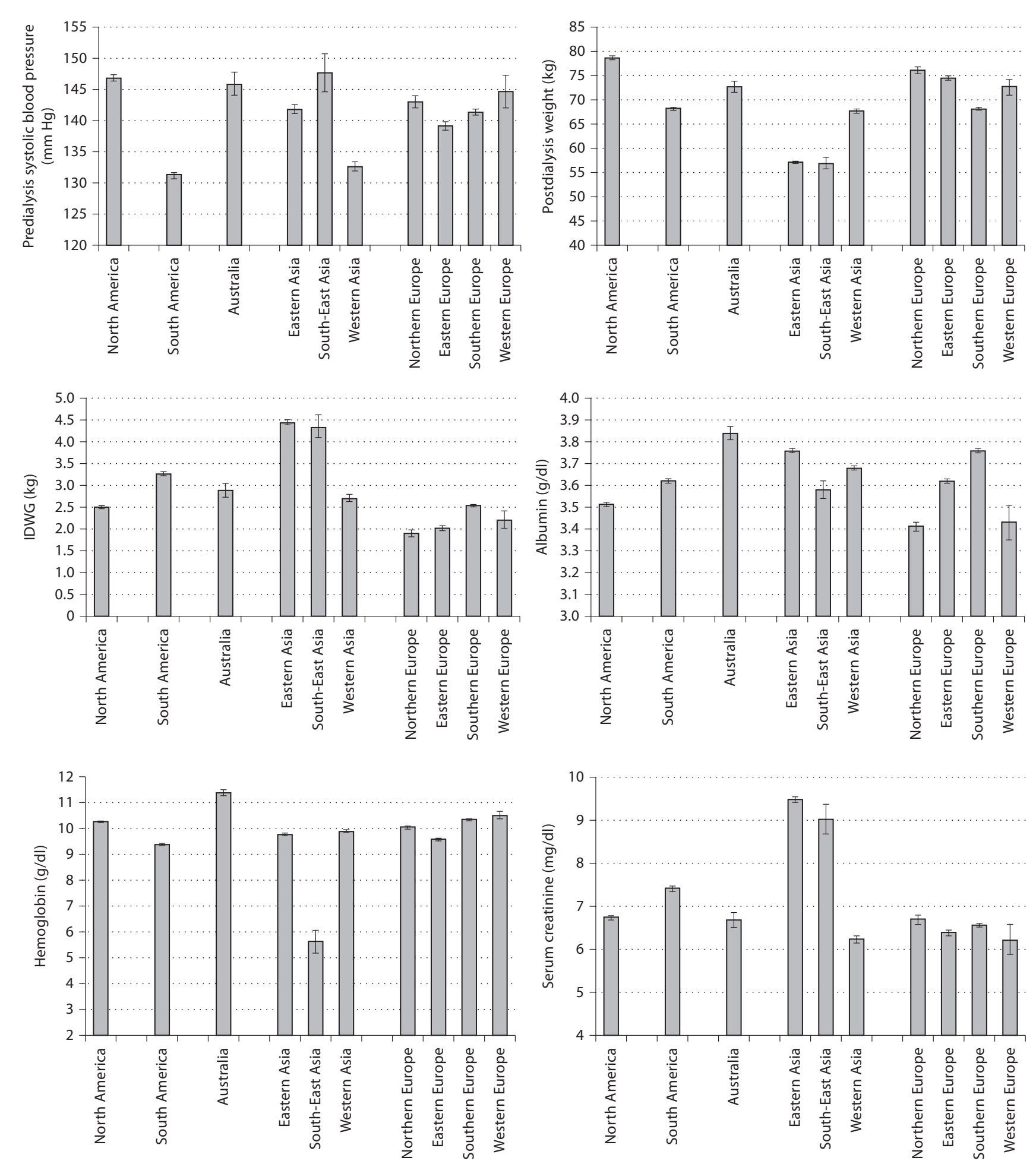

Fig. 2. Clinical and laboratory characteristics of dialysis patients at the start of dialysis by geographic region (mean $\pm 95 \% \mathrm{CI}$ ). 

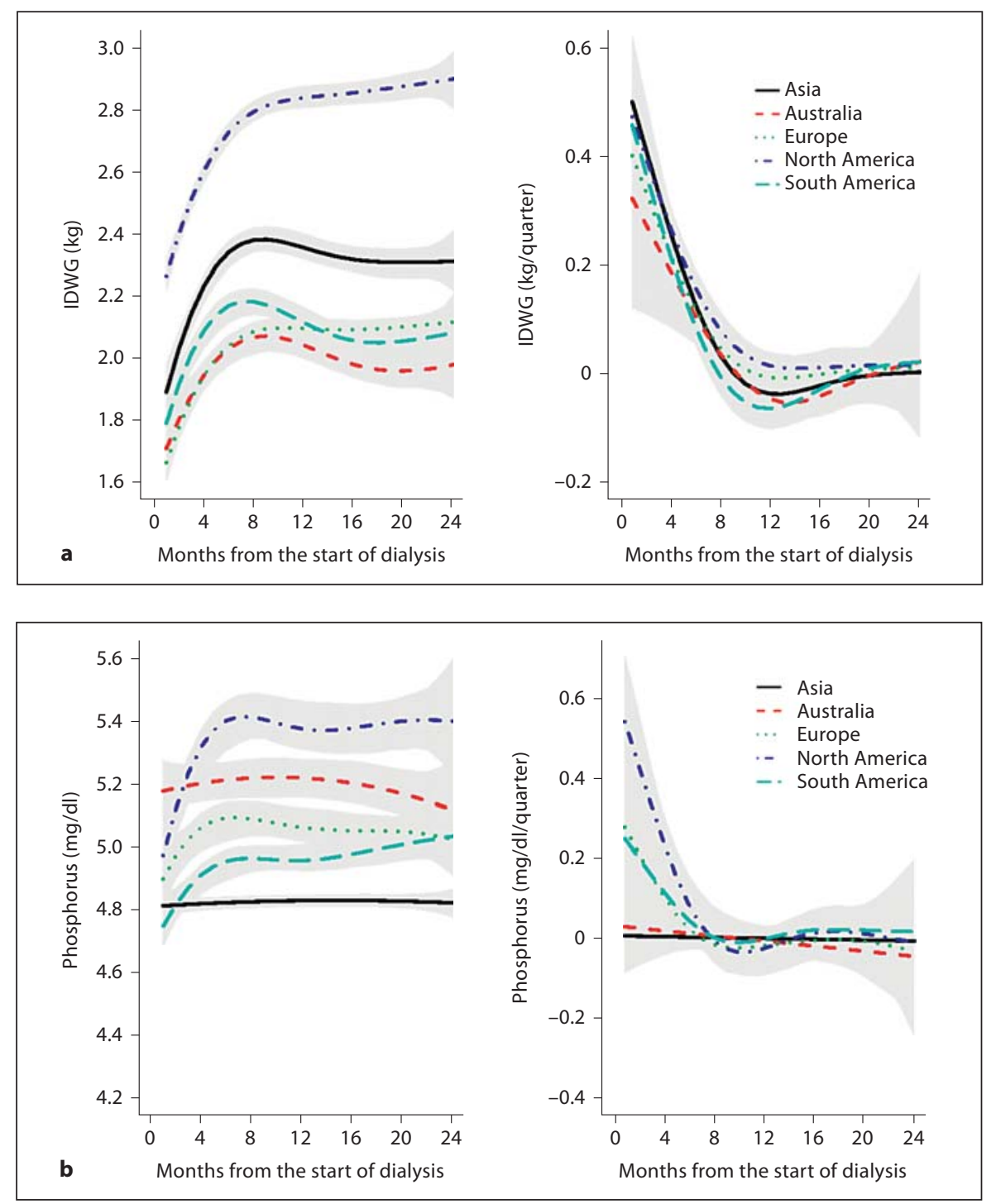

Fig. 3. a Mean IDWG and 95\% CI in the 24 months from the start of dialysis in incident patients who survived for more than 2 years. Left panel: estimates of the partially conditional means; right panel: estimates of rate of change trajectories with 95\% CIs. b Mean serum phosphorus and 95\% CI in the 24 months from the start of dialysis in incident patients who survived for more than 2 years. Left panel: estimates of the partially conditional means; right panel: estimates of rate of change trajectories with 95\% CIs. c Mean NLR and 95\% CI in the 24 months from the start of dialysis in incident patients who survived for more than 2 years. Left panel: estimates of the partially conditional means; right panel: estimates of rate of change trajectories with 95\% CIs.

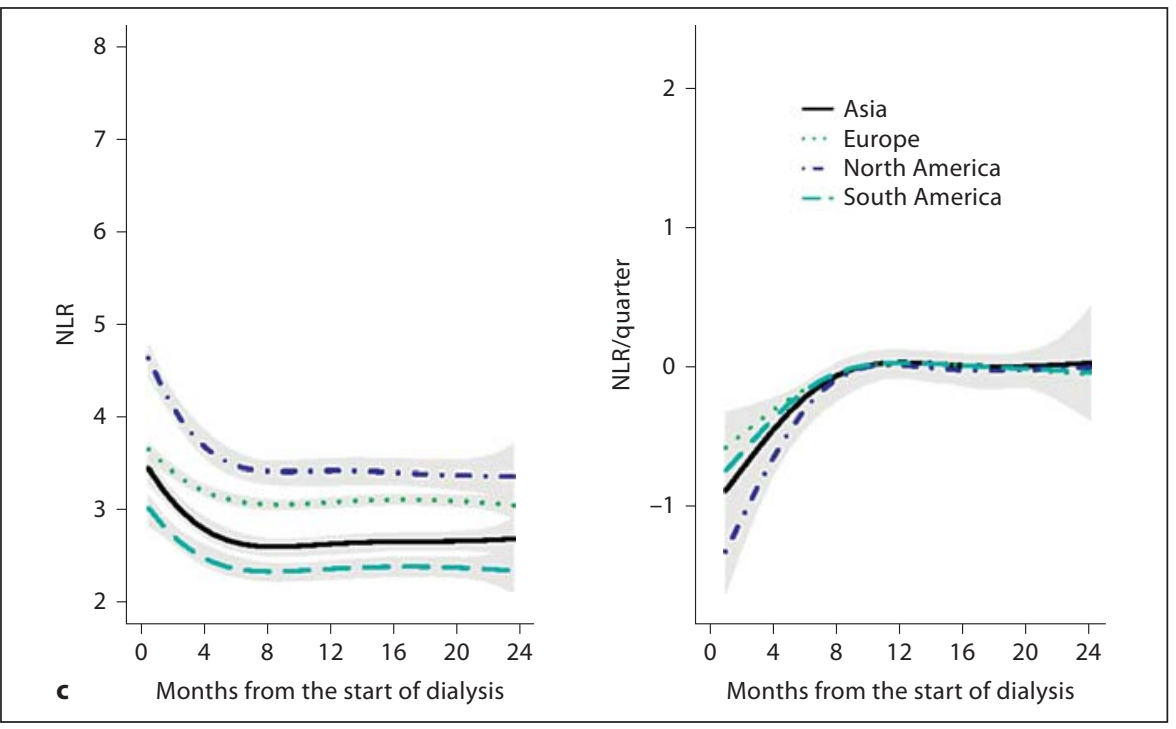




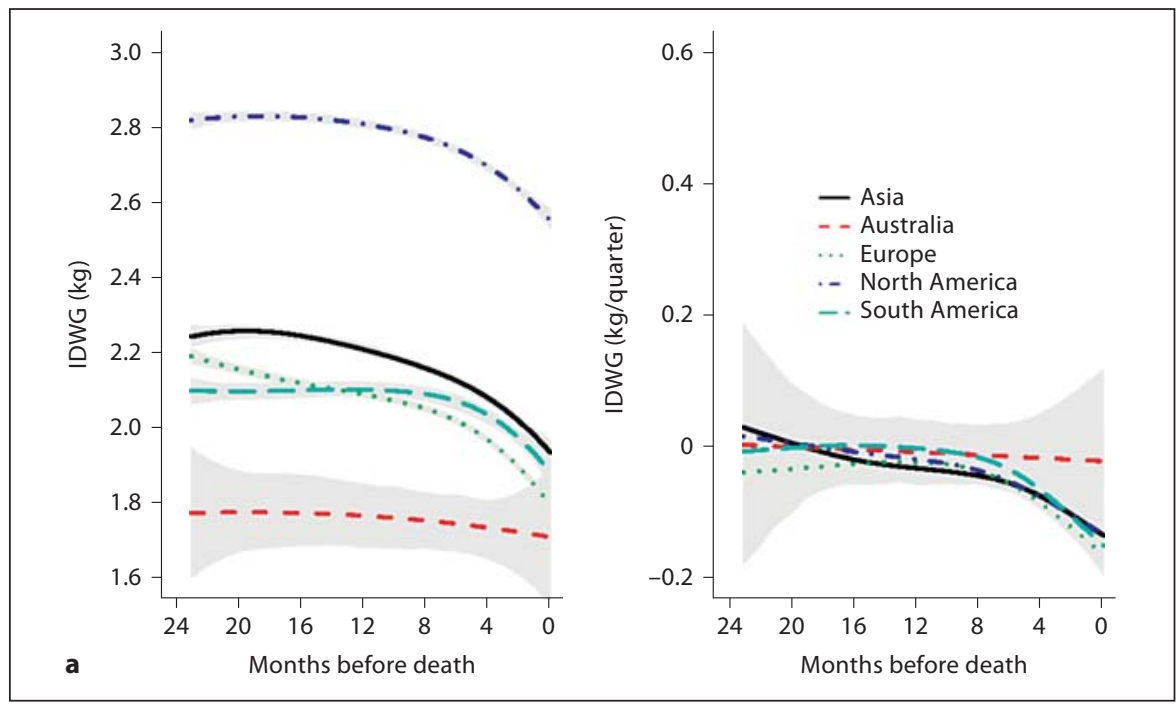

Fig. 4. a Mean IDWG and 95\% CIs in patients in the 24 months prior to death. Left panel: estimates of the partially conditional means; right panel: estimates of rate of change trajectories with $95 \%$ CIs. b Mean serum phosphorus and $95 \%$ CIs in patients in the 24 months prior to death. Left panel: estimates of the partially conditional means; right panel: estimates of rate of change trajectories with $95 \%$ CIs. c Mean NLR and 95\% CIs in patients in the 24 months prior to death. Left panel: estimates of the partially conditional means; right panel: estimates of rate of change trajectories with 95\% CIs.
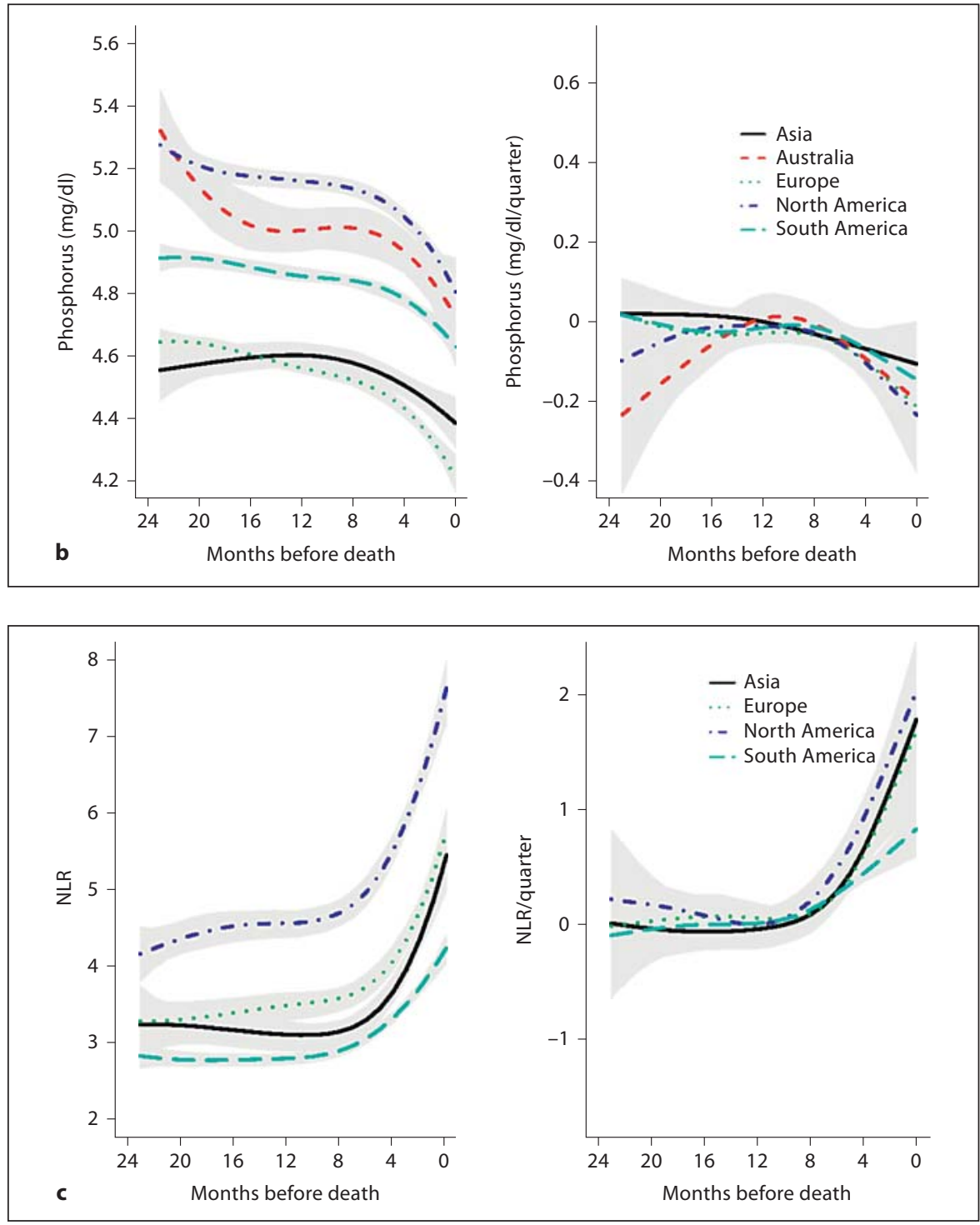
gest poorer nutrition, while increases in NLR may indicate increased inflammation.

Even though MONDO started with a main objective of understanding whether patient clinical and laboratory parameters follow similar trends before death in different countries, we understand that our initiative opens a whole new realm of analyses and insights into what happens in dialysis patients worldwide. In addition to looking at other areas of dialysis research, we plan to add new variables as they become available. For example, we now collect detailed patient hospitalizations, body composition, as well as instrumental tests, such as cardiac echocardiograms and electrocardiograms. We are accommodating our database structure to allow for such a data input. MONDO also plans to expand into other renal replacement therapy modalities, in particular peritoneal dialysis. Other fields of interest are specific patient groups, e.g. children, or patients with rare disorders, e.g. Fabry's disease and microangiopathies.

We anticipate that new members will be joining MONDO in the upcoming years. In July 2012, two dialysis providers (Imperial College Renal and Transplant Center in London, UK, and Hadassah-Hebrew University Medical Center in Jerusalem, Israel) expressed their interest in joining the initiative. Imperial College has databases of nearly 2,000 patients and Hadassah Hospital has a database of 220 patients. Data from Hadassah Hospital is already being incorporated into the current work. Existing MONDO partners are also continuously working on adding new clinics to their networks. Within less than 1 year, we expect to incorporate data on patients from Canada, New Zealand, Thailand, Malaysia, Philippines, South Africa, Brazil, Chile, Colombia and Venezuela. We also believe that data from United Arab Emirates are forthcoming (table 3). MONDO's key strength is the breadth and depth of the data. With data on over 128,000 patients and 22.5 million in-center HD treatments performed in facilities from all continents, this is the largest such initiative to date. Since we rely on the existing EMR system, there is no need for additional data collection forms that need to be completed in clinics. By relying on existing systems, we also have access to data elements that are not readily available. There are no overhead costs associated with entering the MONDO consortium; however, each MONDO member has to carry its costs. Diversity is a key feature of MONDO and thus we hope to bring other dialysis providers with access to patient data and scientific interest on board.

One obvious shortcoming of our initiative is the fact that MONDO members do not necessarily provide fa-
Table 3. Summary of existing and future countries to be included in the MONDO initiative

\begin{tabular}{|c|c|c|c|}
\hline \multirow{2}{*}{$\begin{array}{l}\text { Provider of dialysis } \\
\text { (abbreviated name) }\end{array}$} & \multicolumn{3}{|l|}{ Countries/regions } \\
\hline & existing database & $\begin{array}{l}\text { data to be } \\
\text { added in } \\
<1 \text { year }\end{array}$ & $\begin{array}{l}\text { data to be } \\
\text { added in } \\
>1 \text { year }\end{array}$ \\
\hline $\begin{array}{l}\text { Renal Research } \\
\text { Institute (RRI) }\end{array}$ & USA & & \\
\hline $\begin{array}{l}\text { Maastricht University } \\
\text { Hospital (Maastricht) }\end{array}$ & The Netherlands & & \\
\hline $\begin{array}{l}\text { Hadassah Medical } \\
\text { Center (Hadassah) }\end{array}$ & Israel & & \\
\hline $\begin{array}{l}\text { Imperial College Renal } \\
\text { and Transplant Center } \\
\text { (Imperial College) }\end{array}$ & & UK & \\
\hline $\begin{array}{l}\text { Kingston General } \\
\text { Hospital/Queen's } \\
\text { University (Queen's) } \\
\end{array}$ & & Canada & \\
\hline $\begin{array}{l}\text { Fresenius Asia Pacific } \\
\text { (FMC Asia Pacific) }\end{array}$ & $\begin{array}{l}\text { Australia } \\
\text { China (Hong Kong) } \\
\text { China (Taiwan) } \\
\text { Singapore } \\
\text { South Korea } \\
\end{array}$ & $\begin{array}{l}\text { New Zealand } \\
\text { Thailand } \\
\text { Malaysia } \\
\text { Philippines }\end{array}$ & \\
\hline $\begin{array}{l}\text { Fresenius Medical } \\
\text { Care Europe, } \\
\text { Middle East, } \\
\text { and Africa } \\
\text { (FMC Europe) }\end{array}$ & $\begin{array}{l}\text { Bosnia } \\
\text { Czech Republic } \\
\text { France } \\
\text { Hungary } \\
\text { Ireland } \\
\text { Italy } \\
\text { Poland } \\
\text { Portugal } \\
\text { Romania } \\
\text { Russia } \\
\text { Serbia } \\
\text { Slovakia } \\
\text { Slovenia } \\
\text { Spain } \\
\text { Sweden } \\
\text { Turkey } \\
\text { UK }\end{array}$ & South Africa & UAE \\
\hline $\begin{array}{l}\text { Fresenius Medical } \\
\text { Care Latin America } \\
\text { (Latin America) }\end{array}$ & Argentina & $\begin{array}{l}\text { Brazil } \\
\text { Chile } \\
\text { Colombia } \\
\text { Venezuela }\end{array}$ & \\
\hline Total & 26 & 11 & 1 \\
\hline
\end{tabular}

cilities representative of countries or regions. This deficiency is mitigated to some extent by the large number of patients and facilities enrolled. We also realize that while we have different providers in the consortium, a large fraction of our patients come from the global network of FMC. Another limitation is the over-representation of patients from Europe and Latin America. We try to address this issue by analyzing the data for each region sep- 
arately. Unfortunately, Japan and mainland China are currently not represented. Data from Africa is currently not available, because substantial renal replacement programs are lacking in many African countries. We hope, however, that initiatives like MONDO can highlight the need for advancement of renal replacement therapies in that region.

\section{Conclusion}

While organizationally lean and low-cost, MONDO is the largest global dialysis database initiative to date, with a particular focus on high longitudinal data density and geographical diversity. Longitudinal data are key to understanding pathophysiology and to successful decisionmaking in medicine. With electronic health records becoming more available worldwide, more databases are likely to appear. Our initiative is one such endeavor with the aim to join databases of multiple dialysis providers and academic institutions around the globe. Yet, we also appreciate that MONDO represents only a small fraction of HD patients worldwide. We expect MONDO to grow in the years to come, mainly driven by the realization that many areas of research benefit from a global view.

\section{Acknowledgements}

We thank the MONDO consortium members for their immense contribution to this initiative: Inga Bayh, Aileen Grassmann, Adrian Guinsburg, Eric Liu, Gerdi Klinkner, Neill Duncan, Charles D. Pusey, Laura Scatizzi, Adam Tashman, Stephan Thijssen, Frank van der Sande, and Nathan W. Levin. We also thank all the dialysis centers in the different countries contributing to this analysis. A special thank you to Erika Schuh, Paola Carioni, Peter Kaufmann, Marzio Alunni, and Claudia Amato of the FMC Europe NephroCare Team for their tremendous contribution in putting together the data from patients treated in FMC European countries and Maggie Lam from FMC Asia Pacific for pulling together the data from that region. Also a thank you to Penny Sheppard from RRI for putting this manuscript together.

\section{Disclosure Statement}

Peter Kotanko holds stock in Fresenius Medical Care.

\section{References}

1 Kawamoto K, et al: Improving clinical practice using clinical decision support systems: a systematic review of trials to identify features critical to success. BMJ 2005;330:765.

2 Obama administration calls for electronic health records by 2015, in USA Today.

3 Krishnan M, Wilfehrt HM, Lacson E Jr: In data we trust: the role and utility of dialysis provider databases in the policy process. Clin J Am Soc Nephrol 2012, E-pub ahead of print.

-4 Ounpuu S, Negassa A, Yusuf S: INTERHEART: a global study of risk factors for acute myocardial infarction. Am Heart J 2001;141:711-721.

5 Young E: The Dialysis Outcomes and Practice Patterns Study (DOPPS): an international hemodialysis study. Kidney Int 2000;57: 74-81.

6 Pisoni RL, et al: The Dialysis Outcomes and Practice Patterns Study (DOPPS): design, data elements, and methodology. Am J Kidney Dis 2004;44(suppl 2):7-15.

7 Goodkin DA, Mapes DL, Held PJ: The dialysis outcomes and practice patterns study (DOPPS): how can we improve the care of hemodialysis patients? Semin Dial 2001;14: 157-159.
8 ERA-EDTA Registry: Available from http:// www.era-edta-reg.org/index.jsp? $\mathrm{p}=7$.

-9 Jager KJ, Zoccali C: Clinical databases and the QUEST initiative. Blood Purif 2007;25: 219-220.

10 Eckardt KU, Kasiske BL: Kidney disease: improving global outcomes. Nat Rev Nephrol 2009;5:650-657.

11 LiZ, et al: The epidemiology of systolic blood pressure and death risk in hemodialysis patients. Am J Kidney Dis 2006;48:606-615.

12 Raimann JG, et al: Blood pressure stability in hemodialysis patients confers a survival advantage: results from a large retrospective cohort study. Kidney Int 2012;81:548-558.

13 Kotanko P, et al: Temporal evolution of clinical parameters before death in dialysis patients: a new concept. Blood Purif 2009;27: $38-47$.

14 Usvyat LA, et al: Relation between trends in body temperature and outcome in incident hemodialysis patients. Nephrol Dial Transplant 2012;27:3255-3263.

15 McClellan WM, Flanders WD, Gutman RA: Variable mortality rates among dialysis treatment centers. Ann Intern Med 1992;117: 332-336.

16 Held PJ, et al: Five-year survival for endstage renal disease patients in the United States, Europe, and Japan, 1982 to 1987. Am J Kidney Dis 1990;15:451-457.
17 Clase CM, St Pierre MW, Churchill DN: Conversion between bromcresol green- and bromcresol purple-measured albumin in renal disease. Nephrol Dial Transplant 2001; 16:1925-1929.

18 Kurland BF, Heagerty PJ: Directly parameterized regression conditioning on being alive: analysis of longitudinal data truncated by deaths. Biostatistics 2005;6:241-258.

19 Wang Y: Smoothing Splines: Methods and Applications. New York, Chapman \& Hall, 2011.

20 RDC T, R: A language and environment for statistical computing. Vienna, R Foundation for Statistical Computing, 2009.

21 United Nations Statistics Division (cited 2012 8/20/2012). Available from http://unstats.un.org/unsd/methods/m49/m49regin. htm.

22 Bradbury BD, et al: Predictors of early mortality among incident US hemodialysis patients in the Dialysis Outcomes and Practice Patterns Study (DOPPS). Clin J Am Soc Nephrol 2007;2:89-99.

23 Moist LM, et al: Trends in hemodialysis vascular access from the Australia and New Zealand Dialysis and Transplant Registry (ANZDATA) 2000 to 2005. Am J Kidney Dis 2007;50:612-621. 